\title{
Granulomatous inflammation: A histopathological study
}

\author{
Adhikari RC ${ }^{1}$, Shrestha KB², Sayami G ${ }^{2}$ \\ ${ }^{I}$ Department of Pathology, Tribhuvan University Teaching Hospital, Maharajgunj, Kathmandu, Nepal \\ ${ }^{2}$ Department of Community Medicine \& Public Health, Maharajgunj Medical Campus, Maharajgunj, Kathmandu, Nepal
}

\section{Keywords: \\ Granuloma; Histopathology; \\ Toxoplasmosis}

\begin{abstract}
Background: Granulomatous inflammation is a special type of chronic inflammation that is being a manifestation of many infective, toxic, allergic, autoimmune and neoplastic diseases and also conditions of unknown etiology.

Materials and Methods: The study included a total of 418 granulomatous lesions, diagnosed from January 2010 to December 2012 in the department of pathology, Tribhuvan University Teaching Hospital, Kathmandu, Nepal.

Results: The median age of the patients with granulomatous lesion was 29 years and the majority of the patients were in the age group of 20-29 yrs with slight male predominance. Majority of granulomas were seen in lymph nodes $(41.1 \%)$, followed by skin \& subcutis $(22 \%)$, and bone \& joints $(11.5 \%)$. Tuberculosis was the most common cause of granuloma with $258(61.7 \%)$ cases, followed by fungal infections, foreign body reaction, parasites and toxoplasmosis. Out of 258 cases of tuberculosis, lymph nodes were involved in $140(54.26 \%)$ cases, followed by bone \& joints $(12.79 \%)$ and respiratory system $(5.42 \%)$. The most common type of granuloma was epithelioid $(83.5 \%)$, followed by epithelioid with suppuration and mixed inflammatory.
\end{abstract}

Conclusion: The granulomatous lesion is common in third decade of life with slight male predominance. The commonest site is lymph node with tuberculosis being the most common cause and epithelioid being the most common type of granuloma.

\section{INTRODUCTION}

Granulomatous inflammation is a special type of chronic inflammation, that is being a manifestation of many infective, toxic, allergic, autoimmune and neoplastic diseases and also conditions of unknown etiology. In this inflammation, cells of the mononuclear phagocyte system are predominant

\section{Correspondence:}

Dr. Ram Chandra Adhikari, MD

Consultant Pathologist, Department of Pathology,

Om Hospital \& Research Centre, Chabhil, Kathmandu, Nepal

E-mail:rcadhikari@hotmail.com and take the form of macrophages, epithelioid cells and multinucleated giant cell. In most instances, these cells are aggregated into well demarcated focal lesions called granuloma. ${ }^{1}$ Loose and more diffuse arrangement may be seen. Granuloma formation is usually regarded as a means of defending the host from persistent irritants of either exogenous or endogenous origin.

The provocative agents of granulomatous inflammation appear to be non-degradable by both neutrophils and nonactive macrophages. For such degradation, the action of 
transformed macrophages which are formed with the help of the $\mathrm{CD} 4+\mathrm{T}$ cells is required. The $\mathrm{CD} 4+\mathrm{T}$ cells secrete various mediators such as IL 2, IF $\gamma$, TNF and lymphotoxin for the transformation of the macrophages into epithelioid cells and giant cells. ${ }^{2}$

Causes of granuloma include bacterial, metal-induced, fungal, viral, chlamydial, helminthic, foreign body and unknown cause. ${ }^{3}$ Other causes of granulomatous inflammation are tumor associated, BCG-instillation, sarcoidosis, Crohn's disease, protozoal (toxoplasma, leishmaniasis) \& chalazion.

Granulomas are classified as follows: epithelioid, histiocytic, foreign body, necrobiotic pallisading and mixed inflammatory. ${ }^{4}$ Some epithelioid granulomas are necrotizing, while others show suppuration.

There is often no single histologic feature that distinguishes infectious necrotizing granulomas from other granulomas. ${ }^{5}$ Ancillary studies like special stains (Ziehl-Neelsen, Grocott methamine silver), real-time PCR, In situ hybridization can be performed to find the cause of granuloma. ${ }^{5}$ However, some granulomas remain unexplained even with ancillary studies and in these instances, good clinical history and clinicopathological correlation are essential in making a final diagnosis.

Hence, this study was undertaken to find the frequency and cause of granulomatous lesions.

\section{MATERIALS AND METHODS}

The study was done from January 2010 to December 2012 in the department of pathology, Tribhuvan University Teaching Hospital, Kathmandu, Nepal. This study included a total of 418 granulomatous lesions, diagnosed on Hematoxylin \& eosin stain from all sites. Special stains like Ziehl-Neelsen (ZN), Periodic Acid Schiff (PAS) and Fite-Faraco were used whenever required. The clinical history, other laboratory investigations are radiological findings were collected from the medical records.

Table 1: Age and sex distribution of patients

\begin{tabular}{lccc}
\hline Age group (years) & Male & Female & Total (percentage) \\
\hline 0-9 year & 18 & 7 & $25(6.0)$ \\
10-19 year & 39 & 30 & $69(16.5)$ \\
20-29 year & 60 & 56 & $116(27.8)$ \\
30-39 year & 29 & 43 & $72(17.2)$ \\
40-49 year & 25 & 20 & $45(10.8)$ \\
50-59 year & 36 & 15 & $51(12.2)$ \\
60-69 year & 14 & 13 & $27(6.5)$ \\
70 years and above & 7 & 6 & $13(3.1)$ \\
\hline \multicolumn{1}{c}{ Total } & $\mathbf{2 2 8}$ & $\mathbf{1 9 0}$ & $\mathbf{4 1 8 ( 1 0 0 . 0 )}$ \\
\hline
\end{tabular}

\section{RESULTS}

The median age of the patients with granulomatous lesion was 29 years with a range of 1 to 83 years. The majority of the patients were in the age group of 20-29 years. There was slight male predominance with male to female ratio of $1.2: 1$ (Table 1).

Majority of granulomas were seen in lymph nodes (41.1\%), followed by skin \& sub cutis $(22 \%)$ and bone \& joints $(11.5 \%)$. Other sites were respiratory system, gastrointestinal tract, urinary system, pericardium, male genital system, eye \& ocular adnexae, omentum, oral cavity \& oropharynx, breast $\&$ brain (Table 2).

Granulomas of different etiologies were seen and tabulated in table 3. Tuberculosis (fig.1) was the most common cause of granuloma with 258 (61.7\%) cases, followed by fungal infections, foreign body reaction, parasites and toxoplasmosis. Other causes are leprosy, sarcoidosis, catscratch disease, Crohn's disease, leishmaniasis, tumors, BCG-instillation and chalazion. Final diagnosis was made based on histomorphology, special stains, other laboratory parameters, clinical \& radiological findings and even patient's response to therapy. In 121 (28.9\%) cases, histomorphology, special stains, other laboratory parameters and clinic-radiologic findings could not establish the cause of granulomatous inflammation, so, they were just labeled as granulomatous lesion.

In tuberculosis, $\mathrm{ZN}$ stain was done in 90 cases, out of which 10 cases were $\mathrm{ZN}$ positive (fig.2). Out of 258 cases of tuberculosis, lymph nodes were involved in 140 (54.26\%) cases, followed by bone \& joints $(12.79 \%)$, respiratory system (5.42\%), gastrointestinal system (4.65\%) and female genital system (3.10\%). Fungal elements were demonstrated

Table 2: Site wise distribution of granuloma

\begin{tabular}{clcc}
\hline SN & Site of Granuloma & $\begin{array}{c}\text { Number } \\
\text { of Cases }\end{array}$ & Percentage \\
\hline 1 & Lymph nodes & 172 & 41.1 \\
\hline 2 & Skin and Subcutaneous & 92 & 22.0 \\
\hline 3 & Bone and Joints & 48 & 11.5 \\
4 & Respiratory System & 32 & 7.7 \\
\hline 5 & Gastro-intestinal Tract & 23 & 5.5 \\
\hline 6 & Female Genital Sysem & 10 & 2.4 \\
7 & Urinary System & 10 & 2.4 \\
\hline 8 & Pericardium & 9 & 2.2 \\
\hline 9 & Male Genital System & 6 & 1.4 \\
\hline 10 & Eye and Ocular Adnexae & 6 & 1.4 \\
\hline 11 & Omentum & 4 & 1.0 \\
\hline 12 & Oral Cavity and Oropharynx & 3 & 0.7 \\
\hline 13 & Breast & 2 & 0.5 \\
\hline 14 & Brain & 1 & 0.2 \\
\hline Total & & $\mathbf{4 1 8}$ & $\mathbf{1 0 0 . 0}$ \\
\hline
\end{tabular}


in five cases with PAS stain, which was performed in 13 cases. Out of five cases, three were aspergilloma (fig.3) and two were sporotrichosis. Lung was the site of aspergilloma and skin revealed sporotrichosis.

The most common type of granuloma was epithelioid (83.5\%), followed by epithelioid with suppuration and mixed inflammatory (fig.4). In $97.3 \%$ cases of tuberculosis, the granuloma was epithelioid type. However, fungal infection showed epithelioid granuloma with suppuration in $76.9 \%$ cases. Histiocytic granulomas were seen in fungal and parasitic infections, whereas mixed inflammatory granulomas were seen in parasitic infestation, tuberculosis, chalazion and leishmaniasis (Table4). Necrobiotic granulomas were not seen in this study.

\section{DISCUSSION}

Granulomatous is a distinctive pattern of chronic inflammation encountered in infectious and noninfectious conditions. In this study, granulomatous lesions were common in $3^{\text {rd }}$ decade of life with slight male predominance and this finding corresponds to the finding of other studies. ${ }^{6,7}$ The commonest site was lymph node, followed by skin $\&$ subcutis, bone $\&$ joints, respiratory system and gastro-intestinal tract. In a study of Permi HS et al ${ }^{6}$ the most common site of granulomatous lesion was skin \& subcutis.
Table 3: Causes of granuloma

\begin{tabular}{clcc}
\hline SN & Causes of Granuloma & $\begin{array}{c}\text { Number } \\
\text { of Cases }\end{array}$ & Percentage \\
\hline 1 & Tuberculosis & 258 & 61.7 \\
2 & Fungal & 13 & 3.1 \\
3 & Foreign Body & 7 & 1.7 \\
\hline 4 & Parasites & 3 & .7 \\
\hline 5 & Toxoplasmosis & 3 & .7 \\
\hline 6 & Leprosy & 2 & .5 \\
7 & Sarcoidosis & 2 & .5 \\
8 & Cat-scratch diseases & 2 & .5 \\
\hline 9 & Crohn's Disease & 2 & .5 \\
10 & Leishmaniasis & 2 & .5 \\
\hline 11 & Tumors & 1 & .2 \\
12 & BCG Instillation & 1 & .2 \\
\hline 13 & Chalazion & 1 & .2 \\
\hline 14 & Unknown & 121 & 28.9 \\
\hline & Total & $\mathbf{4 1 8}$ & $\mathbf{1 0 0 . 0 0}$ \\
\hline
\end{tabular}

The most common cause of granuloma in this study and other studies was tuberculosis. However, the second most common cause is fungal in this study, whereas it is leprosy in study of Pawale JS et $\mathrm{al}^{7}$ and Permi HS et $\mathrm{al}^{6}$. Rare causes of granulomatous lesion in this study were chalazion, BCG-instillation, tumor-associated, leishmaniasis, Crohn's

Table 4: Types of granuloma and their causes

\begin{tabular}{|c|c|c|c|c|c|c|}
\hline \multirow{2}{*}{ Causes of Granuloma } & \multicolumn{5}{|c|}{ Diagnosis } & \multirow{2}{*}{ Total (\%) } \\
\hline & $\begin{array}{l}\text { Epithelioid } \\
\text { (\%) }\end{array}$ & $\begin{array}{c}\text { Epithelioid with } \\
\text { Suppuration (\%) }\end{array}$ & $\begin{array}{l}\text { Histiocytic } \\
(\%)\end{array}$ & Foreign Body (\%) & $\begin{array}{c}\text { Mixed } \\
\text { Inflammatory (\%) }\end{array}$ & \\
\hline Tuberculosis & $251(97.3)$ & $6(2.3)$ & 0 & 0 & $1(0.4)$ & $258(100)$ \\
\hline Fungal & $2(15.4)$ & $10(76.9)$ & $1(7.7)$ & 0 & 0 & $13(100)$ \\
\hline Foreign body & 0 & 0 & 0 & $7(100)$ & 0 & $7(100)$ \\
\hline Parasites & 0 & 0 & $1(33.3)$ & 0 & $2(66.7)$ & $3(100)$ \\
\hline Toxoplasmosis & $3(100)$ & 0 & 0 & 0 & 0 & $3(100)$ \\
\hline Cat-scratch diseases & 0 & $2(100)$ & 0 & 0 & 0 & $2(100)$ \\
\hline Crohn's Disease & $2(100)$ & 0 & 0 & 0 & 0 & $2(100)$ \\
\hline Leishmaniasis & 0 & $1(50.0)$ & 0 & 0 & $1(50.0)$ & $2(100)$ \\
\hline Leprosy & $2(100)$ & 0 & 0 & 0 & 0 & $2(100)$ \\
\hline Sarcoidosis & $2(100)$ & 0 & 0 & 0 & 0 & $2(100)$ \\
\hline BCG Instillation & $1(100)$ & 0 & 0 & 0 & 0 & $1(100)$ \\
\hline Chalazion & 0 & 0 & 0 & 0 & $1(100)$ & $1(100)$ \\
\hline Tumors & $1(100)$ & 0 & 0 & 0 & 0 & $1(100)$ \\
\hline Unknown & $85(70.2)$ & $11(9.1)$ & $12(9.9)$ & 0 & $13(10.7)$ & $121(100)$ \\
\hline Total & 349 (83.5) & $30(7.2)$ & $14(3.3)$ & $7(1.7)$ & $18(4.3)$ & 418 (100) \\
\hline
\end{tabular}




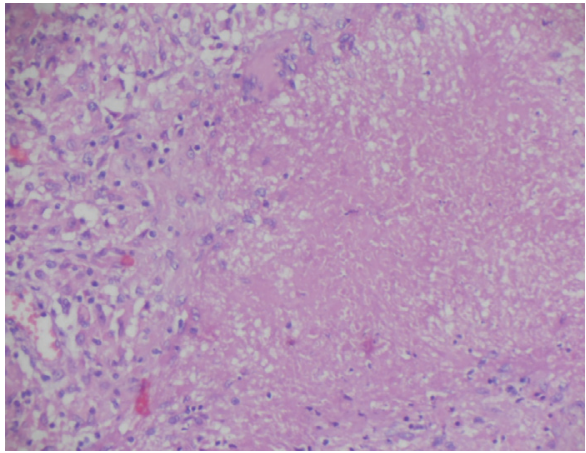

Figure 1: Caseating granulomatous inflammation of lymphnode; consistent with Tuberculosis (HE stain, X100).

disease and Cat-Scratch disease.

ZN stain demonstrated acid fast bacilli only in $11.11 \%$ cases in this study, whereas it was $20.74 \%$ in a study of Permi HS et al, $22.62 \%$ in a study of Pawale JS et al and $71 \%$ in a study of Krishnaswamy $\mathrm{H}$ et al..$^{6-8}$ The low sensitivity of $\mathrm{ZN}$ stain may be due to technical reason. The most common fungal infection is aspergillosis, which is comparable to other studies. Parasitic granulomas were due to cysticercosis and hydatid cyst in this study. In these cases, in addition to granuloma, parasitic structures were demonstrated.

In this study, epithelioid granuloma was the most common type of granuloma, followed by epithelioid with suppuration, mixed inflammatory, histiocytic and foreign body granulomas. Similar to this study, epithelioid type granuloma was most common type in other studies. ${ }^{6,7}$ However, in contrast to this study, the second most common is either foreign body type or histiocytic type in these studies.

Epithelioid granulomas were seen in tuberculosis (97.3\%), toxoplasmosis, fungal, Crohn's disease, leprosy, sarcoidosis, BCG-instillation and tumorassociated. In ourstudy, urothelial carcinoma of urinary bladder, testicular seminoma, Hodgkin lymphoma, mature cystic teratoma and adenocarcinoma of lung showed granulomatous inflammation. In a study of Permi HS et al, granulomas were seen in squamous cell carcinoma of skin, infiltrating ductal carcinoma of breast, papillary carcinoma of thyroid gland, dysgerminoma, Hodgkin lymphoma, seminoma, ameloblastoma and benign cystic teratoma. ${ }^{6}$ Tumor associated granulomatous reaction has largely been attributed to the cytokine milieu of the main tumor or the other cells of the background. ${ }^{9}$ Epithelioid granulomas with suppuration were seen in fungal infection (76.9\%), tuberculosis, cat-scratch disease and leishmaniasis. Histiocytic granulomas were found in parasitic infestation and fungal infections. Foreign body granulomas were seen as a reaction to foreign body. The causes of mixed inflammatory granulomas were parasitic infestation, tuberculosis, leishmaniasis and chalazion.

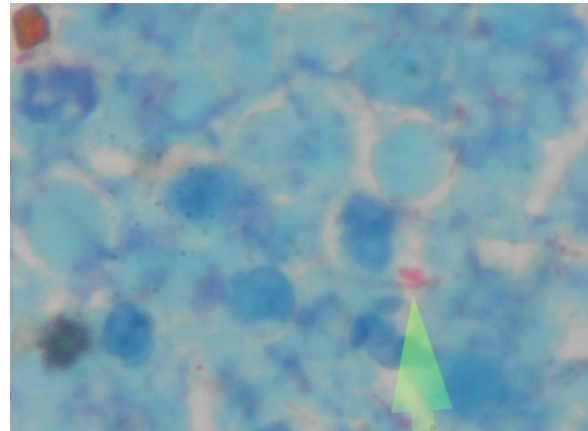

Figure 2: Focus of caseous necrosis showing mycobacterium tuberculosis (ZN stain, X1000).

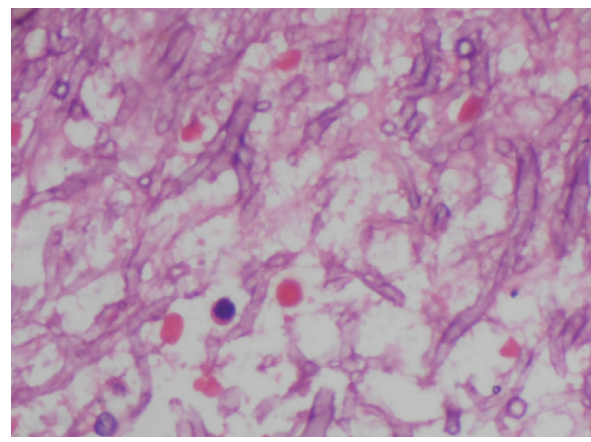

Figure 3: Clumps of dichotomously branching Aspergillus species in lung (HE stain, X400).

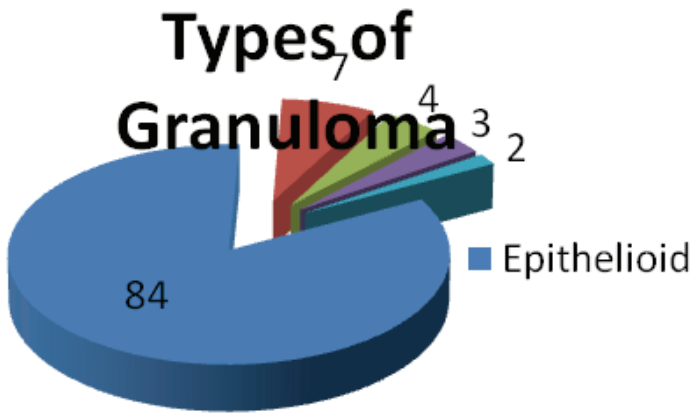

Figure 4: Types of Granuloma

Most of the epithelioid granulomas were necrotizing. As per study of Aubry $\mathrm{MC}$ et $\mathrm{al}^{5}$, the most common cause of necrotizing granulomatous inflammation is infectious and even with ancillary studies, cause of few necrotizing granulomas remain unexplained. Ulbright $\mathrm{TM}$ et $\mathrm{al}^{10}$ suggested that these cases represent infectious granuloma in which micro-organisms have been killed and/or removed by the inflammatory process. Alternative stains i.e. auramine / auramine-rhodamine using fluorescence technique ${ }^{11}$, in-situ hybridization $^{12}$ and real-time polymerase chain reaction ${ }^{13}$ are useful tools to find the cause of granulomatous inflammation.

In significant number of cases $(28.9 \%)$, the cause of granuloma was not known in this study. It may be due to 
limited special stains and unavailability of PCR or ISH like techniques. The use of auramine / auramine-rhodamine using fluorescence technique, in-situ hybridization and realtime PCR may provide specific diagnosis.

\section{CONCLUSION}

The granulomatous lesion is common in third decade of life with slight male predominance. The commonest site is lymph node with tuberculosis being the most common cause and epithelioid being the most common type of granuloma.

\section{REFERENCES}

1. Williams GT, Williams WJ. Granulomatous inflammation - a review. J Clin Pathol 1983;36:723-33.

2. Adams DO. The granulomatous inflammatory response. A review. Am J Pathol 1976;84:164-92.

3. Hirsh BC, Johnson WC. Concepts of granulomatous inflammation. Int J Dermatol 1984;23:90-100.

4. Dhar S. Histopathological features of granulomatous skin diseases, analysis of 22 skin biopsies. Indian J Dermatol 2002;47:88-90.
5. Aubry MC. Necrotizing granulomatous inflammation: what does it mean if your special stains are negative? Mod Pathol 2012;25:531-8.

6. Permi HS, Shetty JK, Shetty PK et al. A histopathological study of granulomatous inflammation. NUJHS 2012;2:15-9.

7. Pawale JS, Puranik R, Kulkarni MH. A histopathological study of granulomatous inflammations with an attempt to find the aetiology. $\mathrm{J}$ Clin Diagn Res 2011;5:301-6.

8. Krishnaswamy H, Job CK. The role of Ziehl-Neelsen and Fluorescent stains in tissue sections in the diagnosis of tuberculosis. Indian $\mathrm{J}$ Tuberc 1974;21:18-21.

9. Bhatia A, Kumar Y, Kathpalia AS. Granulomatous inflammation in lymph nodes draining the cancer: A coincidence or a significant association. Int J Med Sci 2009;1:13-6.

10. Ulbright TM, Katzenstein AA. Solitary necrotizing granulomas in the lung. Am J Surg Pathol 1980;4:13-8.

11. Komareddi S. Abramowsky CR, Swineheart GL et al. Nontuberculous mycobacterial infections: comparison of the fluorescent auramine $-\mathrm{O}$ and Ziehl-Neelsen technique in tissue diagnosis. Hum Pathol 1984;15:1085-9.

12. Hayden RT, Qian X, Roberts GD et al. In situ hybridization for the identification of yeast-like organisms in tissue section. Diag Mol Pathol 2001;10:15-23.

13. Kauffman CA. Histoplasmosis: a clinical and laboratory update. Clin Micro Reviews 2007;20:115-32. 